Supplement of Atmos. Chem. Phys., 21, 8511-8530, 2021

https://doi.org/10.5194/acp-21-8511-2021-supplement

(C) Author(s) 2021. CC BY 4.0 License.

(c) (1)

Supplement of

\title{
Assessing the contribution of the ENSO and MJO to Australian dust activity based on satellite- and ground-based observations
}

Yan Yu and Paul Ginoux

Correspondence to: Yan Yu (yanyu@ princeton.edu)

The copyright of individual parts of the supplement might differ from the article licence. 


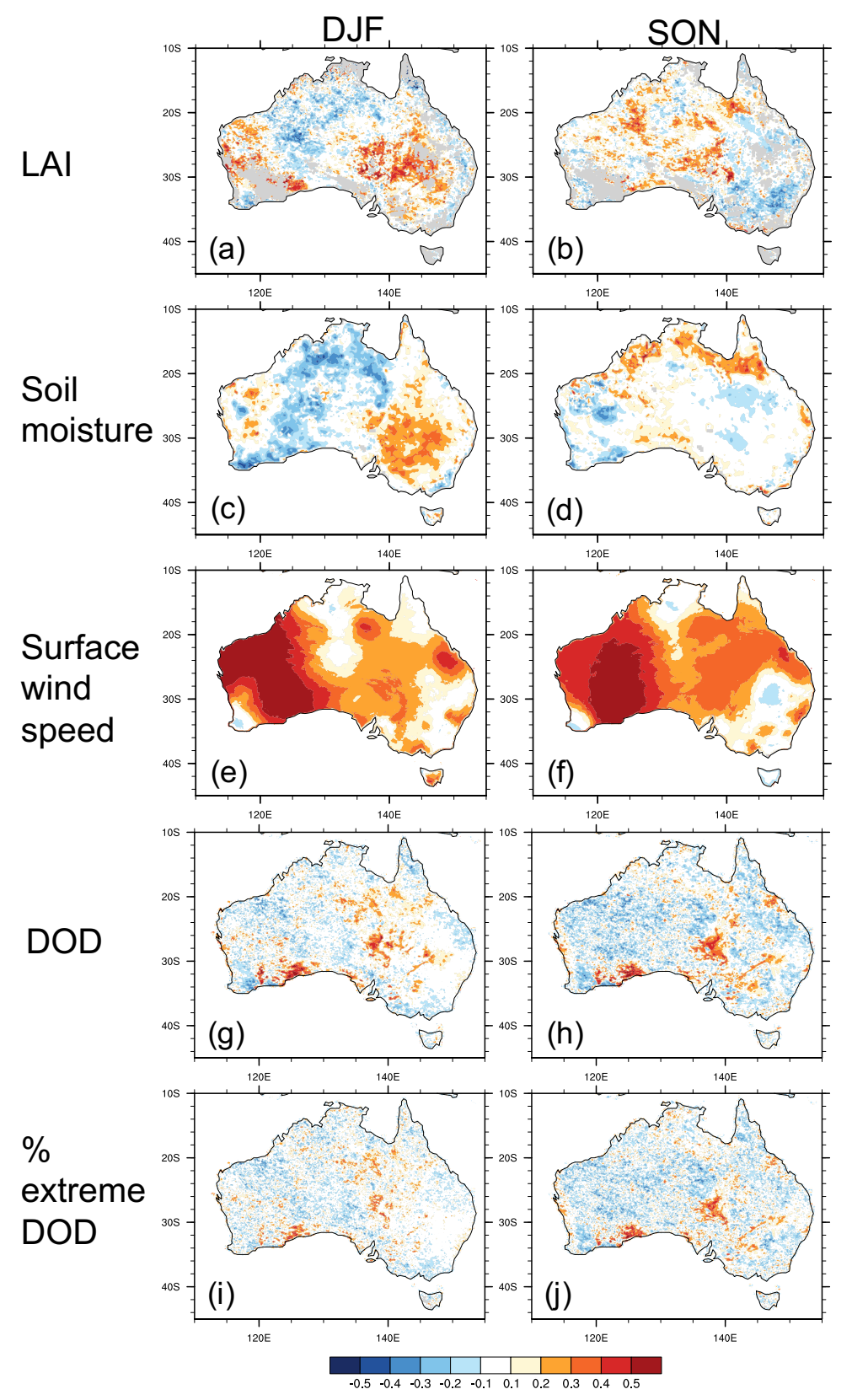

Figure S1 Autocorrelation of the seasonal mean key dust and environmental variables averaged for September-February dust season at one year lag during 2003-2019. 